\title{
Passives in Magahi
}

\section{Lata Atreya $^{1}$, Rajesh Kumar $^{2}$ and Smriti Singh ${ }^{3}$}

\section{Introduction}

This paper deals with passives in Magahi. Magahi is an Indo-Aryan language. Like other Indo-Aryan languages, Magahi shows relatively free word order with Subject-Object-Verb (SOV) as the canonical word order. Magahi has the presence of auxiliary verb in it. Unlike other Indo-Aryan languages Magahi does not have ergative case. Honorificity is one of the major syntactic features found in Magahi. Agreement system in Magahi is only for Person feature of the subject as well as for honorific feature of subject and object.

There has been a substantive amount of work on passivization in other Indo-Aryan languages. Among them, remarkable are Davison (1982) on Hindi, Pandharipande (1979) on Hindi, Marathi and Nepali, Pandharipande (1981) on Hindi, Marathi, Punjabi, Nepali and Kannad (a Dravidian language), Pardeshi (2000) on Marathi, Rosen and Wali (1989) on Marathi, Sahoo (2010) on Oriya and Yadav (1996) on Maithili.

The paper begins with a description of passives in Magahi. It is presented that transitivity and causative form of verb in Magahi are related with the process of passivization. In Magahi, when a causative form of a verb follows an explicator verb jaa-, then it relates to passivized form of the main verb. In Magahi, passive form of verb does not always need explicator verb jaa-, like Hindi or other Indo-Aryan languages. In Magahi, when a verb has a morpheme -aa suffixed to it, the verb becomes passive. Also, inflection -ai- when attached to transitive verb with proper periphrastic form, it results into passivization. It is shown that while regular and capabilitative passives can be accounted for by lexical rule. At the same time inflectional passives in Magahi have properties which can easily be explained as per Government and Binding principles. It is argued that in case of inflectional passives in Magahi, passive transformational rule i.e. NP movement is applicable to Dstructure of passive sentences. Thus passive rule becomes obligatory in case inflectional passives in Magahi.

\section{Passives and Verb Morphology}

In English, passive verb morphology works as follows. A finite form of verb becomes 'to be + past participial' form. In Hindi, verb which is in finite form is changed to 'past participial + present perfective/ past perfective' form of jaanaa. In Magahi, while forming passives morphology may have following types:

a. Past participial suffix -al is added on the active verb stem which follows various form of jaa-. In this case there must be the presence of non-assertive environment like negation, conditional or question for the passive verb.

b. Past participial suffix -aa is added on the active verb stem which follows various form of auxiliary ha-.

c. Verb stem contains the passive suffix -ai which is followed by tense and aspect marker and forms inflectional suffix. This passive suffix - ai is added only on the fused verb form of the compound verb. Intransitive verbs do not undergo inflectional passive formation in Magahi.

Following are the illustration of above morphological changes on active verb while undergoing passivization of verb in Magahi. Sentence (1) is an active sentence. Sentences (2a), (2 b) and (2 c) respectively are illustration of passivization that occurs after the above mentioned morphological changes (a) (b) and (c) on active verb.

$\begin{array}{llll}\text { (1) raam } & \text { kitaab } & \operatorname{lik}^{\mathrm{h}} \mathrm{a} & \text { hai } \\ \text { ram } & \text { book } & \text { write } & \text { is }\end{array}$

'Ram writes a book.'

$\begin{array}{cllllll}\text { (2) a. raam } & \text { se } & \text { kitaab } & \text { nai } & \text { lik }^{\mathrm{h}} \text {-al } & \text { jaa } & \text { hai } \\ \text { ram } & \text { INST } & \text { book } & \text { not } & \text { write-PASS } & \text { go } & \text { is }\end{array}$

'Ram is not able to write the book.'
b. raam se kitaab lik ${ }^{\mathrm{h}}$-aa hai
Ram INST book write-PASS is
'The book is being written by ram.'

\footnotetext{
${ }^{1}$ Research Scholar in the Department of Humanities and Social Science at the IIT Patna

${ }^{2}$ Teaches in Department of Humanities and Social Science at the IIT Madras

${ }^{3}$ Teaches in Department of Humanities and Social Science at the IIT Patna
} 


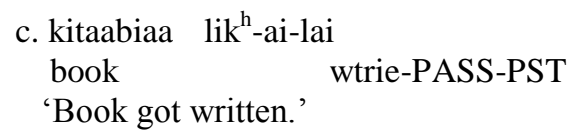

\section{Passive and Transitivity}

Transitivity is a reflection of the thematic structure of the verb. Thematic structure is about the number of arguments a verb can have. Verbs can be intransitive or transitive. When the verb is intransitive it takes no argument as illustrated in (3), whereas, it will have at least one argument if the verb is transitive as illustrated in (4).
(3) raam suta hai
ram sleeps is
'Ram sleeps.'
(4) raam kitaab $\quad \operatorname{lik}^{\mathrm{h}} \mathrm{a}$ hai
ram book write is

'Ram writes a book.'

In sentence (3) verb sut- 'sleep' does not have any argument. The subject NP raam 'Ram' is an external argument and it satisfies EPP (Extended Projection Principle). Therefore, the verb is intransitive. In sentence (4) verb lik ${ }^{\mathrm{h}}$ - 'write' has one argument kitaab to fulfil its thematic structure. Thus, the verb in (4) is transitive in nature. Passivization and transitivity of verb are related to each other. Passivization affects the thematic structure of the verb. In other words, passivization affects the argument holding capacity of the verb. This is elaborated in section (6).

\subsection{Passivization of Intransitive Verb}

In Magahi, similar to other Indo-Aryan languages such as Hindi, Punjabi and Maithili both intransitive and transitive verbs undergo passivization. There is a category of intransitive verbs which cannot be used with an agent. Bhatt and Embick (2003) name them as unaccusatives and not passives. The reason given by them is that passives involve agentivity and these intransitives do not involve agent. Few examples of these intransitives are: baNTa- 'distribute', dh obaa- 'wash', caD ${ }^{\mathrm{h}}$ - 'put upon', ban- 'make' etc. Following illustrations in (5) and

(6) are examples of unaccusative verbs in Magahi.

$\begin{array}{lll}\text { (5) } \mathrm{p}^{\mathrm{h}} \text { uul } & \operatorname{cad}^{\mathrm{h}} \mathrm{a} & \text { hai } \\ \text { flowers } & \text { devotes is }\end{array}$

'Flowers are naturally falling on God.'

(6) citra bana hai

pictures draw are

'Pictures are drawn.'

There are class of intransitive verbs in Magahi that uses agent. These intransitive verbs undergo passivization. Following sentences (7) and (8) illustrate the use of intransitive verb sut- and haNs- respectively.

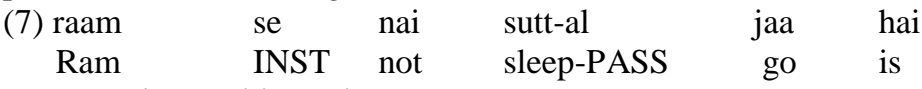

'Ram is not able to sleep.'

(8) sitaa se haNs-al jaa hai kii

Sita INST laugh-PASS go is what

'Is Sita able to laugh?'

Intransitive verbs (except unaccusatives) when passivized always have capabilitative meaning. If the agent is not present in passives of these intransitive verbs, then the sentence is semantically passive as well as of subjunctive mood as illustrated in (9).

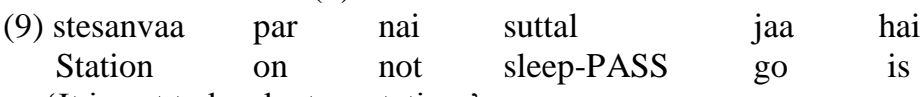

'It is not to be slept on station.'

\subsection{Passives and Transitive verb}

In Magahi, like Punjabi (for details refer Bhatia 1993), transitive passive is ambiguous between regular passive and capabilitative passive. Following sentence in (10a and b) illustrates regular passive reading of transitive verb. Sentences in (11a and b) illustrate capabilitative reading of the transitive verb. 


$\begin{array}{ccccc}\text { (10)a. ciTThiaa } & \text { nai } & \text { lik }^{\mathrm{h}} \text {-al } & \text { jaa } & \text { hai } \\ \text { letter } & \text { not } & \text { write-PASS } & \text { go } & \text { is } \\ \text { 'Letter is being not written, } & & \end{array}$

$\begin{array}{llc}\text { b. } \text { ciTT }^{\mathrm{h}} \text { iaa } & \text { lik } \\ \text { letter } & \text { write-PASS } & \text { hai } \\ \text { 'Letter is being written.' } & \text { is }\end{array}$

$\begin{array}{clclll}\text { (11)a. hamraa-se } & \text { ciTT }^{\mathrm{h}} \text { iaa } & \text { nai } & \text { lik }^{\mathrm{h}} \text {-al } & \text { jaa } & \text { hai } \\ \text { i-ACC/DAT INST } & \text { letter } & \text { not } & \text { write-PASS } & \text { go } & \text { is }\end{array}$

'I am unable to write the letter.'

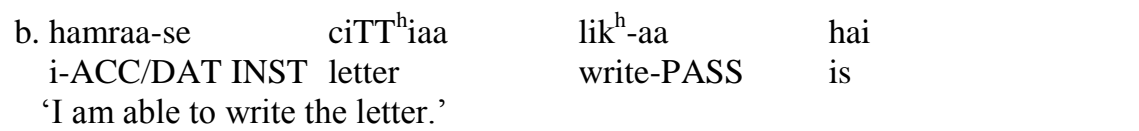

In sentence (10a and $10 \mathrm{~b})$, there is no agent present. However, the passive morphology is present on the verb, resulting into formation of regular passive. In sentence (11a and 11b), agent hamaraa is present, marked with instrumental case -se. The instrumental case on the agent result into expressing the ability of the agent to do a job. Sentence (11a) explains the inability to write a letter by the agent. On the other hand, sentence (11 b) expresses the ability to write a letter by the agent.

\section{Passives and Causatives}

In Hindi, there exist three classes of causative verbs. They are null class, -aa class and -vaa class (Bhatt and Embick 2003). Corresponding to Hindi, in Magahi too, there are three class of causative verb such as null class, -aa class and -baa class. Bhatt and Embick compare - vaa class of causative (Indirect Causative) with passives. They opine that Indirect Causative is built directly on passive structure. The intermediate agent is optional in Indirect Causative and the fact that this agent, when overt, has the case marker that is found with passive agent. In Magahi, all three classes of causative require agent with instrumental case marker - se. - se is the case marker of agent in case of passivization. In Magahi all three classes of causative verb have similarity with passive verb. When the causative verb is used with -jaa or its various forms, the sentence reflects passivization. In case of Null class causative, -al suffix is used with the causative verb. As we saw in section (2) - al is one of the passive suffixes in Magahi and requires non-assertive environment like negation, conditional or question. Thus Null class causative used with -al suffix and followed by -jaa morpheme and non-assertive environment is an illustration of passive in Magahi as illustrated in following sentence in (12).

$\begin{array}{clllll}\text { (12) raam } & \text { se } & \text { kitabiaa } & \text { nai } & \text { lik }^{\mathrm{h}}-\phi \text {-al } & \text { jitai } \\ \text { ram } & \text { INST } & \text { book } & \text { not } & \text { write-CAUS-PST } & \text { go-FUT }\end{array}$

'The book will not be written by Ram.'

Following sentences (13) and (14) in Magahi illustrate -aa class and -baa class of causative verb acting as passives.
(13) raam
INST book
kitabiaa
lik ${ }^{\mathrm{h}}$ - aa-bal
go-FUT $^{\text {jitai }}$

ram INST book
'We will make Ram write the book.'

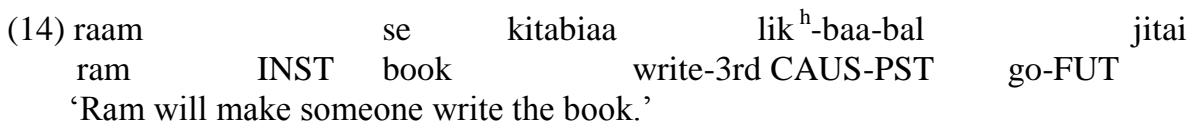

From sentences (13) and (14), an indirect agent is easily inferred. The visible agent raam is with instrumental case just as in passivization. Also, passive morphology -jaa is used with the main verb. Thus, the causatives in sentence (13) and (14) reflect passivization in Magahi.

\section{Inflectional Passives}

Inflectional passive in Magahi is formed by adding suffix - ai on the main verb stem. In this case a verb acts as a single unit and is not followed by any explicator or auxiliary. In Magahi, intransitive verbs cannot be made into inflectional passive. Following sentence (15) and (16) illustrates inflectional passive in Magahi.
(15) ciTT $^{\text {iaa }}$ lik -ai-lai
letter write-PASS-PST 
'Letter was written.'

(16) raam pit-ai-lai

ram beat-PASS-PST

'Ram was beaten.'

From illustration (15) and (16), it is observed that one of the passive morphemes in Magahi, -ai is getting inflected on the main verb lik $^{\mathrm{h}}$ - and pit- (transitive verbs). This suffixation results into formation of inflectional passives in Magahi.

Agent can also be present in inflectional passive. This is illustrated in following sentence (17) and (18).

(17) hamraa-se

ciTT $^{\mathrm{h}}$ iaa

lik ${ }^{\mathrm{h}}$-ai-lai

i-ACC/DAT INST letter

write-PASS-PST

'The letter was written by me.'

(18) maastar-se

$$
\begin{aligned}
& \text { raam } \\
& \text { ram }
\end{aligned}
$$

pit-ai-lai

teacher-INST

beat-PASS-PST

'Ram got beaten by the teacher.'

When agent is present in inflectional passives in Magahi it nowhere leads to capabilitative meaning as it happens in the case of regular passives. In the case of inflectional passives, when agent is present, it simply means as an instrument that does the action under some external factor and does not show its capability. For instance, in sentence (17), the agent ham- 'I' writes the letter under someone's compulsion. Similarly, in sentence (18), the agent maastar 'teacher' is beating the subject raam because of some external factor like raam not following the order of the maastar.

\section{Passives in Magahi: An Analysis}

In Magahi there are three kinds of syntactic passives: Regular passives, Capabilitative passives and Inflectional passives. As we will see, regular passives and capabilitative passives need a lexical rule, at the same time inflectional passives can be accounted for by government and binding theoretic account. Regular passives and capabilitaive passives in Magahi do not show any NP-movement, while inflectional passives are typical example of NP-movement and show A-movement just as English passives. Following section is an illustration of regular and capabilitative passives in Magahi. This section also deals with a theoretical analysis of these two categories of passives.

6.1 Regular Passive and Capabilitative Passive

Following are few example of regular passive and capabilitative passives in Magahi:

(19) a. ham okraaa piTa hiai
i-NOM he-ACC beat is
'I beat him.'

b. hamraa se okraa nai piT-al gelai

i-DAT INST he-ACC not beat-PASS go-PST

'I was not able to beat him.' (Capabilitative passive)

\begin{tabular}{clll}
$\begin{array}{c}\text { c. okraa nai } \\
\text { he-ACC }\end{array}$ & niT-al & \multicolumn{2}{c}{ gelai } \\
& not & beat-PASS & go-PST
\end{tabular}

'He was not beaten.' $\quad$ (Regular passive)
d. hamraa se uu piT-aa hai
i-DAT INST he-DAT beat-PASS is
'I am able to beat him.'
(Capabilitative passive)
(20)a. raam kitaab lik haa $^{\mathrm{h}}$ hai
ram book write is

'Ram writes a book.'

(Active)

$\begin{aligned} & \text { b. raam se } \\ & \text { ram INST book }\end{aligned}$
'Ram is able to write a book.'




\begin{tabular}{|c|c|c|}
\hline $\begin{array}{l}\text { c. kitabiaa } \\
\text { book }\end{array}$ & $\begin{array}{l}\text { lik }^{\mathrm{h}} \text {-al } \\
\text { write-PASS }\end{array}$ & $\begin{array}{l}\text { jaa } \\
\text { go }\end{array}$ \\
\hline
\end{tabular}

'Book is being written.' (Regular passive)

d. ram se kitabiaa lik $^{\mathrm{h}}$-aa hai

ram INST book write-PASS is

'Ram is able to write the book.' (Capabilitative passive)

$\begin{array}{clll}\text { (21)a. mikuaa } & \text { kaduaa } & \text { ropa hai } \\ \text { miku } & \text { pumpkin } & \text { plant is }\end{array}$

'Miku plants the pumpkin.'

b. mikuaa se kaduaa

miku INST pumpkin

'Miku is able to plant the pumpkin.'

c. kaduaa rop-al jaa hai

pumpkin plant-PASS go is

'Pumpkin is being planted.'

$\begin{array}{cll}\text { d. mikuaa } & \text { se } & \text { kaduaa rop-aa } \\ \text { miku } & \text { INST } & \text { pumpkin }\end{array}$

'Miku is able to plant the pumpkin.'

\section{rop-al plant-PASS}

is

hai

plant-PASS
(Regular passive)

(Active)

jaa hai

go is

(Capabilitative passive)

is

(Capabilitative passive)

In Magahi active sentence, the object which is case marked as in sentence (19), where object okraa is case marked with accusative case, retains its case when the active verb takes passive -al suffix and is followed by various forms of jaa-. But the object of the same active sentence looses its overt case mark when changed into another kind of passive where the verb takes the suffix -aa and is followed by auxiliary ha-. This can be observed from sentence $(19 \mathrm{~d})$ where the object uu is without any overt case marker.

Let's account for passives in Magahi, where passive verbs take -al or - aa suffix and is followed by jaaand ha- respectively. In principles and parameter framework (Haegeman, 1994), passive verb morphology absorbs external thematic role and accusative case. Therefore, there remains no external argument in passive construction and the object, which acts as internal argument, is not assigned any case by the passive verb. As a result of this, object or the internal argument moves to empty subject place (which is created due to the absorption of external theta role by the passive verb) and gets nominative case. This does not cause any violation of Case assignment where every overt NP must have a case.

In Magahi passives, as in sentences $(19,20$, and 21) either object retains its case or gets an inherent case. In passive sentence (19b and 19c) the accusative case remains on the patient okraaa. In sentence (19d) the patient has dative case which is inherent and covert. Similarly, in passive sentences of (20) and (21) theme kitaab and kaduaa bears the inherent dative case which is covert. We know that thematic role like patient and theme are usually assigned to objects. Thus, we can say that object in active sentences of (19), (20) and (21) remains as object in their passive form because of the theta role that they posses in the passive forms. Subjects have nominative case in active sentences $(19 \mathrm{a}, 20 \mathrm{a}$ and $21 \mathrm{a})$. They get instrumental case - se in passive sentences. The thematic role of agent or actor indicates that they are subject even in the passive sentences $(19 \mathrm{~b}$ and $19 \mathrm{~d}),(20 \mathrm{~b}$ and $20 \mathrm{~d})$ and (21b and 21d).

From the above sentences in Magahi, we observe that external argument and internal argument of active sentence retains there position in passive sentence. Thus in (19a) ham is the external argument of active verb piT- which remains external argument in the passive form (19b and 19d). Similarly okraa is the internal argument of the active verb piT- which remains as internal argument in passive form (19b, 19c and 19d). The same pattern is observed from sentences (20) and (21). In sentence (20) raam is the external argument and kitaab is the internal argument of the active verb lik $^{\mathrm{h}}$ - which retains their argument position in the passive form $(20 \mathrm{~b}$, $20 \mathrm{c}$ and 20d). We note that in sentences (19c), (20c) and (21c) where the agent is not present, there is an implied agent. Thus, in these sentences external argument position is occupied by null agent. The passive morphology al and -aa in Magahi does not absorb either external theta role or accusative case. Therefore, object remains at object position and subject retains its theta role and also remains at its own position. Thus, we can say that passive morphology - al and -aa do not induce any kind of movement of subject or object. These passives can be simply accounted for by a lexical rule which can be stated as follows:

(22) NP (NOM), NP (ACC), V $\rightarrow$ NP (INST), NP (ACC/DAT) V+-al + jaa-/ V + -aa + ha-/jaa- 
However, there exists a third kind of passive in Magahi, inflectional passives, which act as English passives. This is explained in the next section 6.2.

6.2 Inflectional Passives

In the above section we observed a description of the passives in Magahi with -al and -aa suffix on the verb. These types of passives can be accounted for by a simple lexical rule. Let's look at some examples of inflectional passives in Magahi. Following are examples of inflectional passives in Magahi as passive inflection -ai is getting suffixed on the main verb.

$\begin{array}{ll}\text { (23) ciTThiaa } & \text { lik } \\ \text { letter } & \text { write-PAi } \\ \text { lLetter } & \text { was }\end{array}$

'Letter was written.'

(24) raam piT-ai-lai

ram beat-PASS-PST

'Ram was beaten.'

(25) hamraa-se

ciTT $^{\mathrm{h}}$ iaa $\quad$ lik $^{\mathrm{h}}$-ai-lai

i-ACC/DAT INST letter

write-PASS-PST

'The letter was written by me.'

(26) maastar-se raam piT-ai-lai

teacher-INST ram beat-PASS-PST

'Ram got beaten by the teacher.'

Sentences (23) and (24) are inflectional passives without agent. They are semantically complete, similar to English passives as illustrated in following sentence (27).

(27) A letter was written.

Magahi inflectional passives when expressed with agent as in sentences (25) and (26), agent acts as an adjunct. Semantically hamraa se is not needed to complete the meaning of the sentence (30). From sentence (23) and (24), we find that NP is taking nominative case. As we know only subjects are assigned nominative case. Thus the NP ciTT $^{\mathrm{h}}$ iaa in (23) and NP raam in sentence (24) are subjects. Let's see the active counterpart of these inflectional passives:

(28) ham $\quad$ ciTT $^{\mathrm{h}}$ iaa lik $^{\mathrm{h}} \mathrm{a}$ hiai

i letter write is

'I write a letter.'

(29) maastar raam ke piTaa hai

teacher ram ACC beat is

'Teacher beats Ram.'

Sentence (28) is the active counterpart of passive sentences (23) and (25). Sentence (29) is the active counterpart of passive sentences (24) and (26). In the active sentences ciTT ${ }^{\mathrm{h}}$ iaa and raam act as object while in the passive they act as subject. Thus object of active sentence is becoming subject of passive sentence. Along with this subject of active sentence ham in (28) and maastar in (29) are becoming adjunct in passive (25) and (26). Following are the D-structure and S-structure of passive sentence (25) in Magahi.

D-structure of sentence (25) in Magahi:

(30) hamraa-se [IP e [I, [vP [v lik ${ }^{\mathrm{h}}$-ai-] ciTT ${ }^{\mathrm{h}}$ iaa] -lai]]

$\mathrm{S}$-structure of sentence (25) in Magahi:

(31) hamraa se [IP ciTT $^{\mathrm{h}}$ iaa $_{\mathrm{i}}$ [I, [vP [v lik ${ }^{\mathrm{h}}$-ai] $\mathrm{t}_{\mathrm{i}}$ ]-lai]]

In inflectional passive in Magahi due to absorption of accusative case by the suffix -ai, the object ciTT $^{\mathrm{h}}$ iaa losses its case marker and becomes case less at D-structure. To have case it moves to empty subject position which is created by the absorption of external theta role by the passive inflection -ai. Empty subject position is a case position by virtue of being a subject position. Thus internal argument ciTT ${ }^{\mathrm{h}}$ iaa moves to the empty subject position ' $\mathrm{e}$ ' and gets nominative case. This is an instance of A-movement. At D-structure ciTT ${ }^{\mathrm{h}}$ iaa gets theta role by virtue of being internal argument of the verb lik $^{\mathrm{h}}$-. Thus ciTT ${ }^{\mathrm{h}}$ iaa gets both a theta role and a case as a chain is created. Similar to English passive this chain is assigned one theta role at the foot position and one case at its head position. The passive inflection -ai is absorbing external theta role so subject ham becomes an 
adjunct. In other words, Magahi passive inflection -ai absorbs both external theta role and structural case just as English passive suffix -en, as outlined in Jaeggli (1986) and Roberts (1987).

\section{Conclusions}

This paper exclusively discusses the passivization in Magahi. Verbs undergo morphological changes in passives. The three morphological changes are suffixation of $-\mathrm{al}$ or $-\mathrm{aa}$ or $-\mathrm{ai}$. Intransitive verbs (except unaccusatives) when passivised always have capabilitative meaning. In Magahi -aa class and -baa class causative verbs when used with explicator - jaa are considered as naturally passive. It is found that regular and capabilitative class of passives in Magahi can be accounted for by lexical rule. At the same time, it is discussed that inflectional passive morpheme in Magahi absorbs external theta role and structural case as outlined by Jaeggli (1986) and Roberts (1987) for English passive morpheme -en.

\section{References}

[1]. A Davison, On the form and meaning of Hindi passive sentences, Lingua, 58:1-2, 1982, 149-179.

[2]. R Pandharipande, Passive as an optional rule in Hindi, Marathi and Nepali, In B. Kachru, H. H. Hock and Y. Kachru (Eds.), South Asian languages analysis, 1 (Dept. of Linguistics, University of Illinois, Urbana-Champaign, 1979) 89-106.

[3]. R Pandharipande, Syntax and semantics of the passive construction in selected South Asian languages, 1981, www.proquest.uni.com

[4]. P Pardeshi, The passive and related construction in Marathi, In R. Singh (Ed.), The yearbook of South Asian languages 2000, (Sage Publication, Thousand Oaks/London/New Delhi, 2000) 147-171.

[5]. C Rosen and K. Wali, Twin passives, inversion, and multistratalism in Marathi, Natural Language and Linguistic Theory, 7: 1, 1989, 1-50.

[6]. A Sahoo, Oriya passives with diatransitives, LAEL-5 PG Conference Proceedings, Lancaster University: Lancaster, UK, 2010.

[7]. R Yadav, A reference grammar of Maithili (Mouton De Gruyter: Berlin/New York, 1996).

[8]. R Bhatt and D. Embick, Causative derivations in Hindi, 2003, http://people.umass.edu/bhatt/papers/bhatt-embick.caus.pdf

[9]. T K Bhatia, Punjabi: A cognitive descriptive grammar (Routledge: New York, 1993).

[10]. L Haegeman, Government and binding theory ( $2^{\text {nd }}$ Ed.) (Blackwell Publishing: Malden, 1994).

[11]. O Jaeggli, Passive, Linguistic Inquiry, 17, 1986, 587-633.

[12]. I Roberts, The representation of implicit and dethematized Subjects (Dordrecht: Foris, 1987). 